\title{
Sandwich Panel Behavior for Core Loading Beyond the Yield Limit
}

\author{
Salih Akour ${ }^{1} \&$ Hussein Maaitah ${ }^{2}$ \\ ${ }^{1}$ The University of Jordan, School of Engineering, Mechanical Engineering Department, Amman, Jordan \\ ${ }^{2}$ Al Balqa University, Faculty of Engineering and Technology, Mechanical Engineering Department, Amman, \\ Jordan \\ Correspondence: Salih Akour, The University of Jordan, School of Engineering, Mechanical Engineering \\ Department, PO Box 13512, Amman 11942, Jordan. Fax: 962-6535-5588. E-mail: akour@ju.edu.jo
}

Received: January 25, 2018

Accepted: February 4, 2018

Online Published: February 28, 2018

doi:10.5539/mas.v12n3p117

URL: https://doi.org/10.5539/mas.v12n3p117

\begin{abstract}
The effect of loading core material beyond its yield limit on sandwich panel behavior is investigated. Different core materials of different stiffness are studied. The panel modeled using a finite element analysis package. Simply supported boundary conditions are applied on all sides of the panel. The effect of core stiffness is investigated parametrically by utilizing univariate search optimization technique. The load has been increased in quasi-static steps till face sheets reach the yield point. The model has been validated analytically and experimentally for selected cases. The finite element model results show very good agreement with the analytical and the experimental results investigation. It is proved in this study that the load carrying capacity of the panel increases as the core material goes beyond the yield point. Load transmitted to the face sheets increases as the core stiffness gets softer. As core material is getting stiffer face sheets of sandwich panel yield before the core.
\end{abstract}

Keywords: sandwich panel, foam core, beyond yield stress, finite element analysis

\section{Introduction}

New materials typically bring new challenges to designer who utilizes these new materials. In the past decades various sandwich panels have been implemented in aerospace, marine, architectural and transportation industry. Light-weight, excellent corrosion characteristics and rapid installation capabilities created tremendous opportunities for these sandwich panels in industry. Sandwich panel normally consists of a low-density core material sandwiched between two high modulus face skins to produce a lightweight panel with exceptional stiffness as shown in Figure 1. The face skins act like the flanges of an I-beam whereas the core works like web by spacing the facing skins and transfers shear between them to make the composite panel work as a homogeneous structure. The faces are typically bonded to the core to achieve the composite action and to transfer the forces between the components.

According to the literature the first book about sandwich structures was written by (Plantema, 1966), followed by a book written by (Allen, 1969), and more recently by (Zenkert, 1995). A method to design for minimum weight and reported the failure mode map of sandwich construction was developed by (Triantafillou \& Gibson, 1987); however the method did not consider the post yield state of the sandwich structure. (L.L. Mercado, Sikarskie, \& Miskioglu, 2000) reported that the load carrying capacity by sandwich structures continue to increase after core yielding. Knowing that the core could not carry additional load after yield, this increasing load carrying capacity of post yield sandwich structure initiates the postulation that the additional shear load was transferred to the face sheets. To account for the above-mentioned phenomenon, (L. L. Mercado \& Sikarskie, 1999) developed a higher order theory by including a bilinear core material module. This theory yields a fairly accurate prediction on the deflection of a foam cored sandwich structure in four point bending. In addition, this theory does not take into account the core compression under localized load, or any geometric non-linearity. The classical sandwich beam theory also assumes that in-plane displacements of the core through its depth are linear. In other words, it was assumed that the core thickness remains constant and cross-sections perpendicular to the neutral axis remain plane after deformation. This assumption is generally true for traditional core material such as metallic honeycomb. However, this assumption is not suitable for soft, foam-based cores, especially when the sandwich structure is subjected to a concentrated load. With a much lower rigidity compared to metallic honeycomb, foam-based cored sandwich structures are susceptible to localized failure. Insufficient support to the 
face sheets due to core compression near the application points of concentrated loads can lead to failures such as face sheet / core delamination, face sheet buckling, and face sheet yielding. This localized non-linearity is reported by many researchers (Caprino \& Langella, 2000; Gdoutos, Daniel, Wang, \& Abot, 2001; Thomsen, 1993, 1995). The shear distribution at localized failure points has not been well defined.

To design an efficient sandwich structure, it is vital to understand the behavior of each layer in the structure. Classical sandwich theory, higher order theory by (L.L. Mercado et al., 2000) and high order theory developed by (Frostig, Baruch, Vilnay, \& Sheinman, 1992) could predict the sandwich panel behavior fairly accurate in the linear range. However, these theories could not give an accurate prediction of the sandwich structure behavior after core yielding. Large deflection of sandwich structures due to core yielding could vary the direction of the applied load on the structure. Recently (Akour \& Maaitah, 2012) studied the effect of the loading area on the behavior and they reported that loads distributed over small areas lead to local dentation in the face sheet and local yielding for the sandwich panel core. Also (Akour, Maaitah, \& Nayfeh, 2012) studied the effect of sandwich panel core thickness and they found that increasing the core thickness results higher load carrying capacity of the sandwich panel and the panel behavior gets closer to the I-Beam behavior.

Finite element (FE) analysis is utilized to investigate the response of sandwich panel under distributed load. Geometric nonlinearity and material nonlinearity are considered in this investigation to unveil the behavior of sandwich panel beyond core yielding. The effect of core stiffness is investigated. Four core materials are utilized to cover the stiffness range from $37.5 \mathrm{MPa}$ to $402.6 \mathrm{MPa}$. Univariate search optimization technique is adopted in studying these parameters (Chapra \& Canale, 2006).

\section{Method}

The methodology includes the physical model, the finite element model, the experimental setup and procedure for utilized in the experimental verification, and theoretical varication of the finite element model.

\subsection{Physical Model}

The sandwich panel consists of two face sheets made of metal. The thickness of each face sheet is $\mathbf{t}$. Soft core of c thickness is sandwiched between those face sheets. The core material is made of foam which is soft compared to the face sheets. The panel is square in shape. The side length is designated by a whereas the overall thickness is designated by $\mathbf{h}$. Figure 1 illustrates the sandwich panel geometry. The values of $\mathbf{a}, \mathbf{t}$ and $\mathbf{c}$ are $608 \mathrm{~mm}, 1.0 \mathrm{~mm}$ and $50 \mathrm{~mm}$ respectively.

This research takes into account the geometric non-linearity as well as the material nonlinearity. The following assumptions are made to simplify the model without losing the physics of the problem

1. Face sheets and core are perfectly bonded: no de-lamination occur between layers. Future study is to extend the delamination effect.

2. Face sheets remain elastic all the time: Due to the significantly higher yield strength and modulus of elasticity of the face sheets compared to the core, face sheets are assumed to remain elastic throughout the loading. The analysis stops when the face sheets start to yield.

3. Geometric non-linearity has a significant effect: Geometric non-linearity is considered to have significant effect on the load distribution on each layer of the sandwich structure.

4. The panel is simply supported from all sides.

5. Out of plane load is applied and varied in quasi-static manner.

Due to the symmetry only quarter of the sandwich panel is modeled. The loading area is square in shape; its side length is $100 \mathrm{~mm}$ for full panel dimension. However for quarter model of the panel, the side length is $50 \mathrm{~mm}$. The load is applied to the sandwich top face sheet as a distributed load which is increased gradually (step by step) till face sheet stress reaches the yield limit of the face sheet material. A distributed load is applied on the top surface of the sandwich panel. The area on which the distributed load is applied is located at the middle of the top face sheet plate. The loading area at the middle top face of sandwich panel is square in shape. 


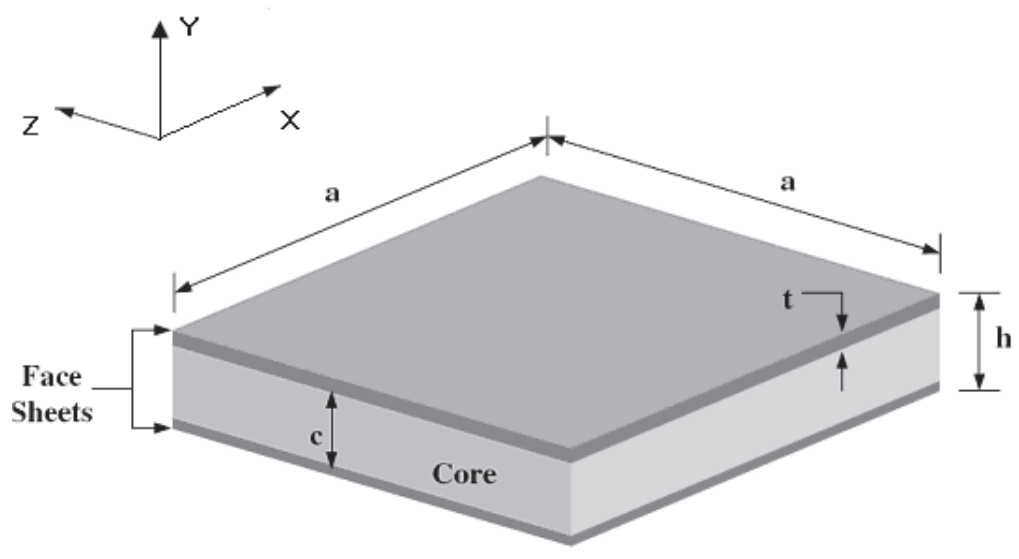

Figure 1. Illustration sandwich plate geometry

Four different materials are investigated. The influence of core material stiffness on the performance of the sandwich plate is studied. Their modulus of elasticity is varying from $37.5 \mathrm{MPa}$ through $138.6 \mathrm{MPa}, 180 \mathrm{MPa}$, and 402.6 MPa. Table 1 presents the materials used in the current investigation. The first row presents the mechanical properties of the face sheet material while the rest are the core materials. For FEM analysis the aluminum metal face sheet is utilized whereas for experimental verification commercial steel metal face sheet is utilized. The corresponding stress strain curves of the core materials A through D shown in Table 1 can be found in reference (Akour \& Maaitah, 2010). These materials are selected because of their wide usage in the industry.

Table 1. Compression of sandwich panel material properties

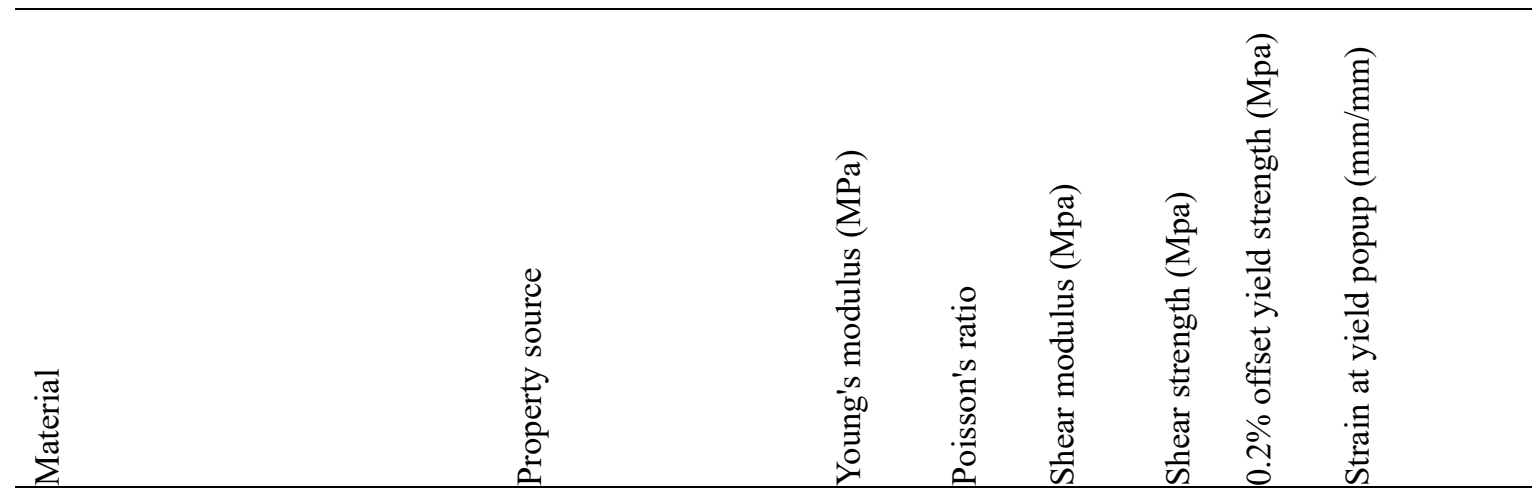

Face sheet: Aluminum 3003-H14 (Boyer \& Gall, 1991) 69,000 $0.33 \quad 25,000 \quad 120 \quad 145 \quad$ Not available

Core A : AirexR63.50

Core B: H100

Core C: Herex C70.200

Core D: H250
(Rao, 2002)

(Kuang-An, 2001)

(Rao, 2002)

(Kuang-An, 2001) $\begin{array}{llllll}37.5 & 0.335 & 14.05 & 0.45 & 0.637 & 0.019\end{array}$

$\begin{array}{llllll}138.6 & 0.35 & 47.574 & 1.2 & 1.5 & 0.0108225\end{array}$

180

$\begin{array}{lllll}0.37 & 65.69 & 1.6 & 2.554 & 0.0162\end{array}$

$\begin{array}{llllll}402.6 & 0.35 & 117.2 & 4.5 & 5 & 0.014\end{array}$

\subsection{Finite Element Model}

The FE package used in the development of the FE models is I-DEAS (Master Series 10, 1999). The relatively robust and user-friendly solid modeling, and FE meshing interface are the main advantages of this solid modeling/ finite element software. 
The non-linear analysis capabilities of I-DEAS are utilized in carrying the FE analyses of the model which includes geometric non-linearity and material nonlinearity. Load is applied to the model in quasi-static manner by utilizing the load increment module of I-DEAS. Load increments are applied slowly during the analysis (i.e. simulates exactly the real life). The type of analysis done for this research effort is "static, non-linear analysis".

The symmetric nature of the problem allows only quarter of the whole panel to be modeled and meshed. The boundary conditions applied are shown on Figure 2 .

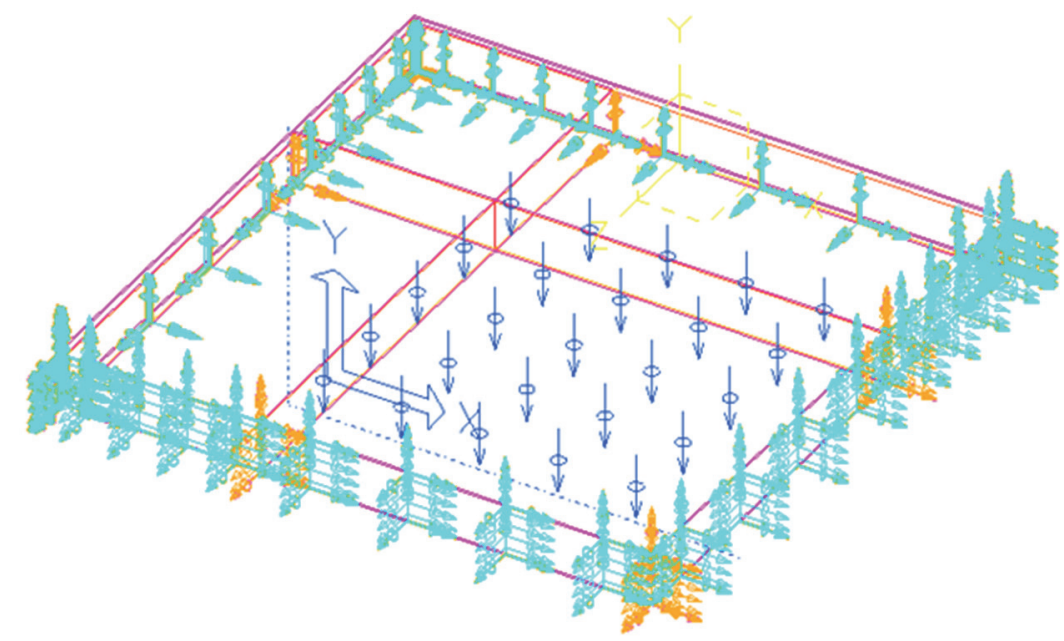

Figure 2. Sandwich panel boundary condition (cyan arrows) and loading (blue arrows)

The two planes of symmetry of the panel have symmetry boundary conditions. A simply supported boundary condition is applied to the other two sides of the quarter panel. A distributed load is applied on the top surface of the sandwich panel. The area on which the distributed load is applied is shown in Figure 2.

The FE software is set in such a way to solve the model at each load step. This allows each case to be done in a single run of the finite element model. As a result of this, the model would take less memory space because one single solid model and FE model can be used for all load steps of each case.

The numerical model utilizes the map meshing facility in I-DEAS. By controlling the number of nodes along each edge of the solid model, this function provides full control of the mesh size. The mesh is refined till the changes in the result are less than $0.5 \%$. Constant mesh density is applied using the mapped meshing function. This is important because constant mesh density ensures that data collected from any region of the plate are of the same degree of resolution. Three-dimensional (solid) brick elements are used in this analysis. Second order (parabolic) brick elements are chosen over the first order (linear) brick elements in order to better interpolate the data between nodes.

Since the analysis involves material non-linearity, a yield function or yield criteria needs to be defined for the model. Von Mises yield criteria and its associated flow rule is used in this analysis. Isotropic hardening is also used to describe the changes of the yield criterion as a result of plastic straining. Only the core elements are assigned a yield function due to the assumption that only core yielding occurs throughout the loading process. The face sheets are assumed to remain elastic at all the time; hence no yield function is assigned to the face sheet elements. However the yield point of the face sheet material is fed to the software to be used as indicator for stopping the analysis.

\subsection{Model Verification}

To assure accuracy and validity of the results the model is verified experimentally and analytically. For experimental verification, selected cases are examined and compared with the FEM. Analytical model is produced based on the classical sandwich panel theory. The analytical solution covers only the elastic range whereas the experimental covers both the elastic and plastic ranges.

\subsubsection{Experimental Verification}

The following subsections explain the test setup utilized in the verification, the mechanical properties and the analysis of experimental results. The analysis show how close the experimental results to the FEM. 


\section{Test Setup}

Here is a description of the experimental setup used in the study. It consists of the following:

1. The Specimens have been manufactured. Core of the sandwich panel is made of polyurethane foam. Top and bottom sheets of the sandwich panel are made of steel. The side length a of panel used for verification is $250 \mathrm{~mm}$. the Mechanical properties of the sheet metal and the core are obtained experimentally based on the corresponding ASTM Standard tests (ASTM-C273-94, 1994; ASTM-C297/C297M, 2004; ASTM-C365/C365M-11a, 2011; ASTM-D6416/D6416-99, 1999; ASTM-E8/E8M-13a, 2013). Steel sheet metal faces are used in the experimental verification instead of the Aluminum sheets due to the unavailability of the Aluminum sheets at the time of the experiment conduction. However the FEM was modified for steel and the comparison analysis were carried out.

2. Fixture for applying simply supported boundary condition is produced. Figures 3 show different views of the fixture.

3. The test is performed on a uniaxial testing machine that is shown in Figure 4. The system is a vertical column-tester, hydraulically driven, and with direct display of the force. The maximum testing force is 50 $\mathrm{kN}$. In the working space, tensile force as well as compressive force can be applied. Distributed load is applied to the specimen by adaptors manufactured for this purpose. Figure 5 illustrates the adapters used in experimental setup that is square in shape and has side length of $d$. Different sizes of these adapters are produced to perform the experiments that are correspondent test specimens.
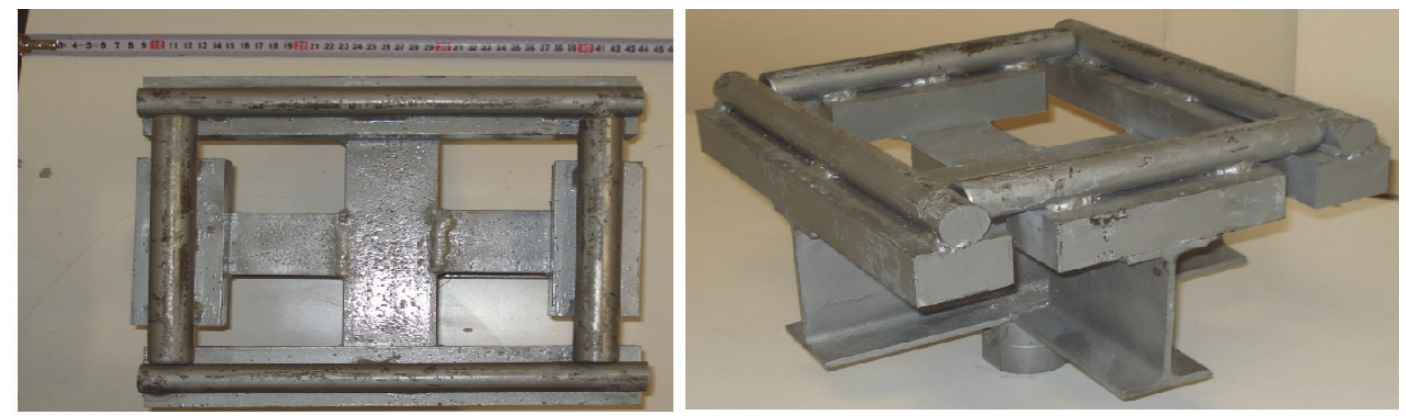

Figure 3. Presentation of the fixture that is produced for applying simply supported boundary condition (different views)

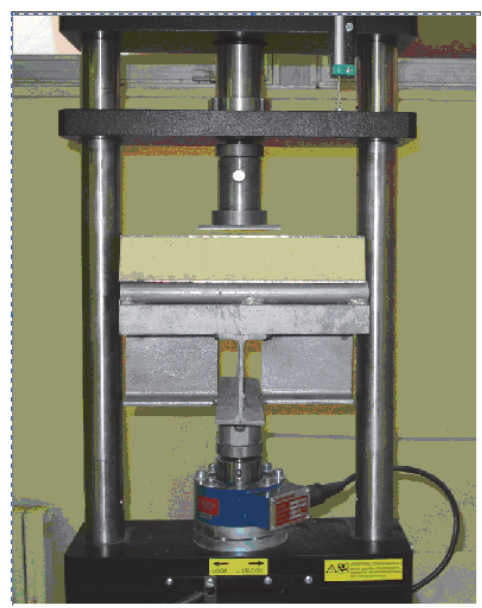

(a)

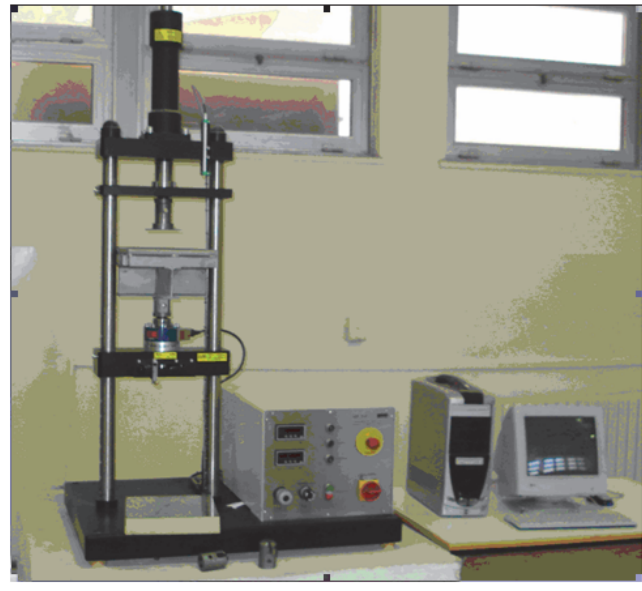

(b)

Figure 4. Uniaxial testing machine a) with specimen and b) without specimen. 


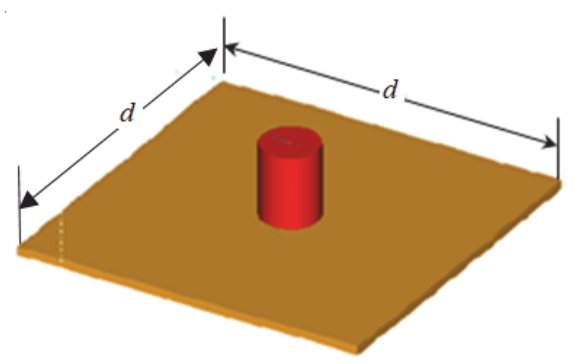

Figure 5. Illustration of the adapters used in the experiments for applying distributed load on specimen, where $d$ is the side length

\section{Mechanical Properties of the Specimen}

The sandwich panel is made of polyurethane foam and steel sheets. The mechanical properties are obtained experimentally for both the core and the sheets by utilizing the following standards: (ASTM-C273-94, 1994) Standard test method for shear properties of sandwich core materials, (ASTM-C297/C297M, 2004) Standard Test Method for Flatwise Tensile Strength of Sandwich Constructions, (ASTM-C365/C365M-11a, 2011) Standard Test Method for Flatwise Compressive Properties of Sandwich Cores, (ASTM-E8/E8M-13a, 2013) Standard Test Methods for Tension Testing of Metallic Materials tests.

\section{Analysis}

(ASTM-D6416/D6416-99, 1999) Standard Test Method for Two-Dimensional Flexural Properties of Simply Supported Sandwich Composite Plates Subjected to a Distributed Load is utilized in conduction the testing for the sandwich panel. The experiments are carried out and the relation between the applied load and the deflection of the specimen center point is recorded. Figure 6 and Figure 7 presents the experiment and FEM results for core thickness $49 \mathrm{~mm}$ and $71 \mathrm{~mm}$ respectively. It may be seen that the results are in very good agreement.

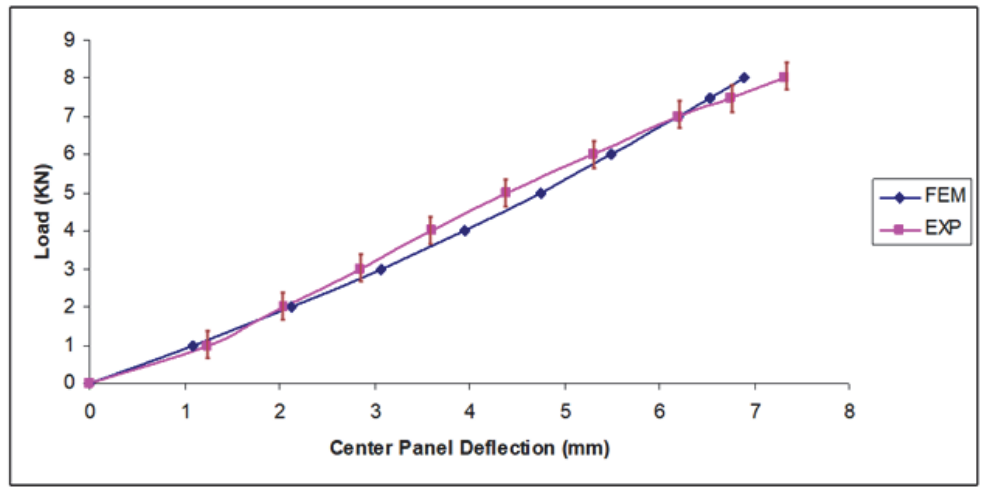

Figure 6. Comparison of load versus center deflection for core thickness $=49 \mathrm{~mm}$, Sheet Thickness $=0.5 \mathrm{~mm}$, applied load area $=200 \mathrm{~mm} * 200 \mathrm{~mm}$

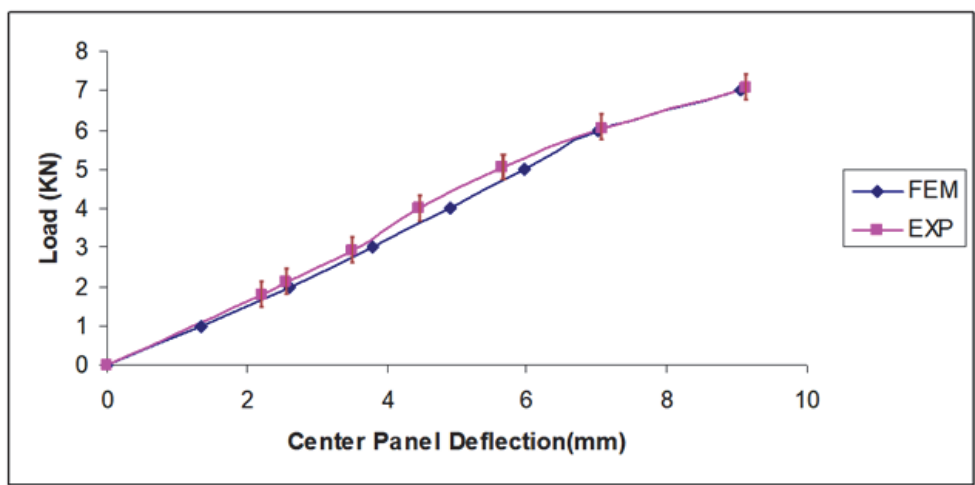

Figure 7. Comparison of load versus center deflection for core thickness $=71 \mathrm{~mm}$, sheet Thickness $=0.5 \mathrm{~mm}$, applied load area $=150 \mathrm{~mm} * 150 \mathrm{~mm}$ 
To assure accuracy of the experimental results, the experiment is performed many times and the average of the readings is plotted. The variation in the experimental results dose not exceeds $7 \%$ of the average value. The error bars in Figures 6 and 7 show the range of variation of the experimental values over the mean value.

\subsection{Analytical Verification}

Classical sandwich theory has been utilized to obtain close form solution (Zenkert, 1995). The equations that are derived are programmed using Matlab Software. Appendix A presents the analytical model utilized in the verification. The comparison between the numerical and theoretical models in the linear range are presented in Figures 8 (a), (b) and (c). These Figures demonstrates very good agreement between theoretical and numerical solution.

The classical sandwich plate theory is used to compare and validate the numerically predicted shear distribution of the plate in the linear range. Comparison between the numerically determined shear distribution and the classical sandwich plate theory distribution is made for all load steps. It is assumed that the core carries the entire shear load in the linear range. Figures 8(a), (b) and (c) show the total shear resultant obtained by the finite element model against the theoretical model in the linear range. The data is collected at three load steps $17.2 \mathrm{KPa}$, $34.5 \mathrm{KPa}$ and $51.7 \mathrm{KPa}$. The relative difference between the theoretical and the finite element results does not exceed $1 \%$.

\section{Results and Discussion}

The core material (different materials with different modulus of elasticity) is varied for studying its influence on the sandwich panel behavior. The main advantage of this investigation over the sandwich panel theory is that both geometric and material nonlinearities are considered without approximation. Usually these approximations eliminate part of the problem physics. By utilizing "I-DEAS' pre and post processing module, stress and it is all components, strain and it is all components including the plastic strain, and deformations are obtained.

It is clear from Figure 9 (a) that the plastic deformation occurs close to the panel support (close to the area where boundary conditions are applied). The stress distribution is similar for all panels. The criterion that is adopted by this investigation, at what load step the FE model should stop is, either when anyone of the face sheets starts to yield or when the core material reaches the fracture limit. This criterion fulfills the designer need; in general, design engineers try to avoid panel permanent distortion or failure. As soon as the face sheet metal starts to yield, this means that permanent deformation is taking place. So all produced results do not exceed the loading that could cause face - sheet yielding. Von mises stress contour and deformation contour are presented in Figures 9 (b) and 9 (c) respectively. Figure 9 (b) shows that the stress is high near the edges and at the center of the core where the load is applied. Figure 9 (c) illustrates maximum deformation at the center of the panel.

Figure 10 (a), (b) and (c) demonstrate the effect of material stiffness. Since the modulus of elasticity is $\mathrm{E}_{\mathrm{A}}<\mathrm{E}_{\mathrm{B}}<$ $E_{C}<E_{D}$, it can be seen that the softer the material is, the more load is transferred from core material to the sheet metal as the core starts to yield. The horizontal lines presented in Figure 10 (a) represent the shear strength of materials A, B and C. Each line has the same mark of its corresponding material. It is obvious that the load carrying capacity of the panel increases as its core material stiffness increases. It may be seen that in Figure 10 (a) the core material is still within the elastic range for $\mathrm{C}$ and $\mathrm{D}$; however in Figure 10 (b) in the bottom face sheet starts to yield (entering the plastic range). As the core starts to yield, its maximum-stress increment-rate starts to decrease (see Figure 10 (b) and (c)) whereas the maximum-stress incremental-rate of the bottom - face - sheet starts to increase, this means that the load is being transferred to the face sheet-metal. This is the main advantage of increasing the load beyond the yield limit of the core material.

It is demonstrated in Figures 10 (a), (b) and (c) that as the stiffness of core material increases the load carrying capacity of panel increases. The increment of shear stress with respect to strain decreases as the load increases. In yield range, the post yield deformation rate of the core material is higher than that of the elastic range for the same load increment as presented in Figure 10 (a). This deformation works as a mechanism of transferring the excess load to the face sheets. For example panel A in Figures 10 (a), (b) and (c) the core reaches yield point at $1580 \mathrm{kPa}$ load and it is stress stays constant while the bottom and top sheets stress keeps increasing.

As illustrated in Figure 9 (a) and (b), the metal material starts to yield (entering the plastic range) close to the support (where the boundary conditions are applied). This is physically true, the distributed load over the loading area becomes reaction force concentrated on the strip area on which the boundary conditions (simply supported boundary condition) are applied, i.e., distributed load is converted to concentrated load. So the area where the boundary conditions are applied reaches the yield stress range before any other part of the panel. The graphs 
show that sheet material D has reached the yield point before the core material. This can be referred to the high stiffness of its core material, i.e., the panel gets closer in its behavior to isotropic plate.

It can be seen from Figure 10 (b) and (c) that the load carrying capacity has increased for materials $\mathrm{C}$ and $\mathrm{D}$ on the expense of low loading for the core material. The worst situation is for material D where the stress is almost half way to the yield limit (see Figure 10 (a) and Table 1). The material $\mathrm{C}$ is not much better than $\mathrm{D}$ because both the sheet metal and the core reach the yield limit almost at the same load. Materials A and B have gone beyond the yield limit and provide increase in the load carrying capacity. It is obvious in Figure 10 (b) that material A reached yield at load $1580 \mathrm{KN}$ which is presented by the vertical line (that has the same mark as material A) and the yield of the bottom face sheet is reached at load $2632 \mathrm{KN}$ (horizontal line in the graph). The difference between these two loads is the amount of increase in the load carrying capacity of material A, i.e. $67 \%$ increase in the load carrying capacity. For material $\mathrm{C}$ the yield load (vertical line) of the core material is almost the same load of bottom face sheet i.e., the vertical line on Figure 10 (b) that is correspondent to material $\mathrm{C}$ intersects with the curve of material $\mathrm{C}$ at the same point. The increase in the load carrying capacity of material $\mathrm{C}$ does not exceed $4 \%$. The percent increase in the load carrying capacity against the core to face sheet modulus of elasticity ratio that is obtained from FEM results analysis is plotted in Figure 11. Increasing the stiffness ratio beyond 0.0026 is of no benefit in gaining higher load carrying capacity as a result of increasing the load beyond the core yield limit. It may be seen that the relative increase of load carrying capacity is about $67 \%$ to $59 \%$ for the range 0.0005 to 0.002 respectively. However it starts to decrease after stiffness ratio 0.002 till it reaches $4 \%$ at 0.0026 .

The results of this work are generated according to the univariate search optimization technique (Chapra \& Canale, 2006). Based on this numerical optimization technique, the data has been produced by utilizing the parametric optimization module of 'I-DEAS' software.

\section{Conclusions}

Investigation of sandwich panel behavior beyond core material yield is carried out. The investigation is accomplished in sight of the core material nonlinearity and the geometric nonlinearity of the whole panel. This model is validated against selected analytical and experimental cases. The model shows very good agreement with both the analytical and the experimental results and the max difference with FE model is $1 \%$ and $7 \%$ respectively.

The effects of core material stiffness necessary in designing sandwich panels are unveiled. It is also proved that the load carrying capacity of sandwich panel can be improved by loading the panel beyond the core yield limit. This load is going to be transmitted to the face sheet as long as the core material is relatively soft. The maximum increase in load carrying capacity achieved is $67 \%$ at stiffness ratio of 0.0005 .

Increasing the stiffness of the core material to a certain extent leads to face sheet yielding before the core material. It is proved that increasing core stiffness increases the load carrying capacity of the sandwich panel. Increasing the stiffness ratio beyond 0.0026 , this will lead to toward a behavior close to the isotropic plat.

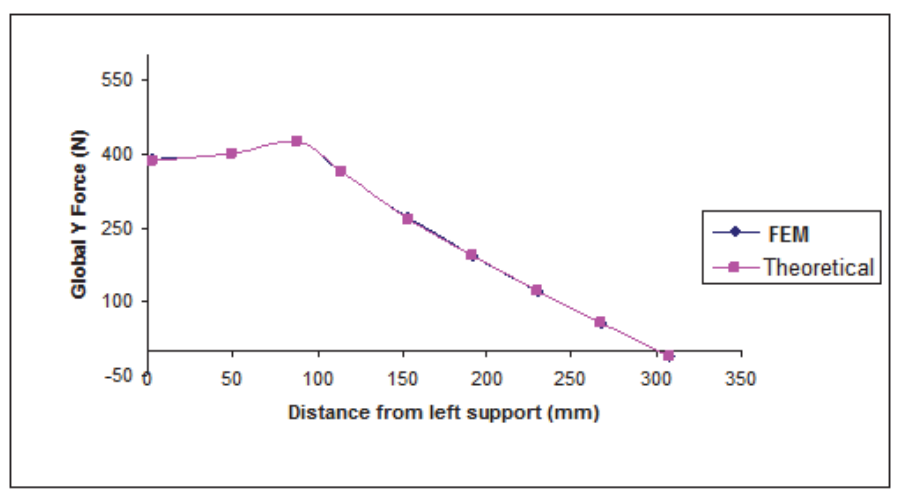

(a) 


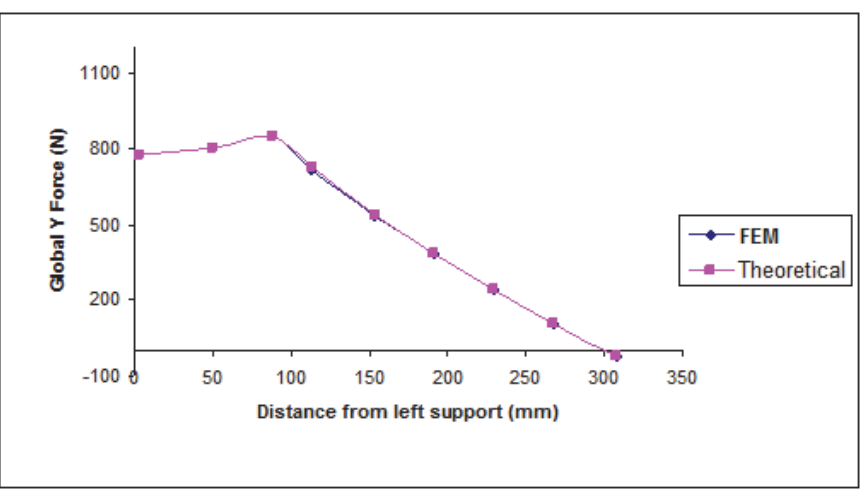

(b)

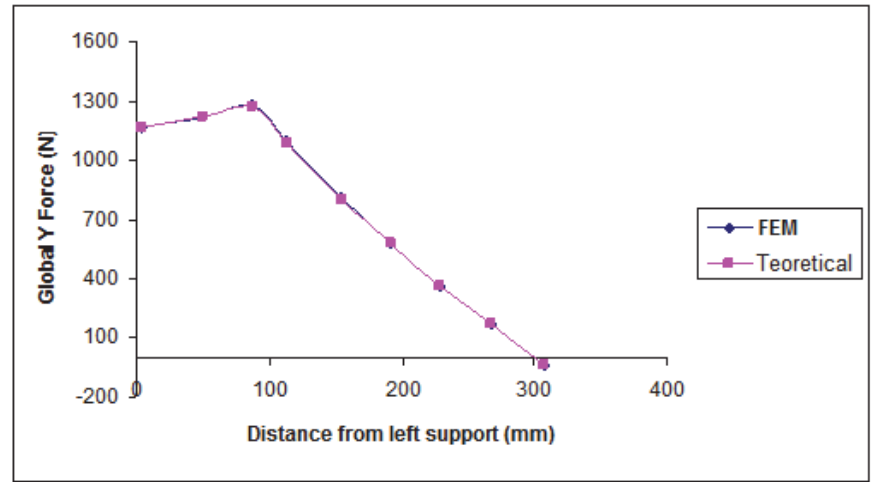

(c)

Figure 8. Total plate shear distribution comparison along X-axis at load a) $17.2 \mathrm{kPa}, \mathrm{b}) 34.5 \mathrm{kPa}$ and c) $51.7 \mathrm{kPa}$
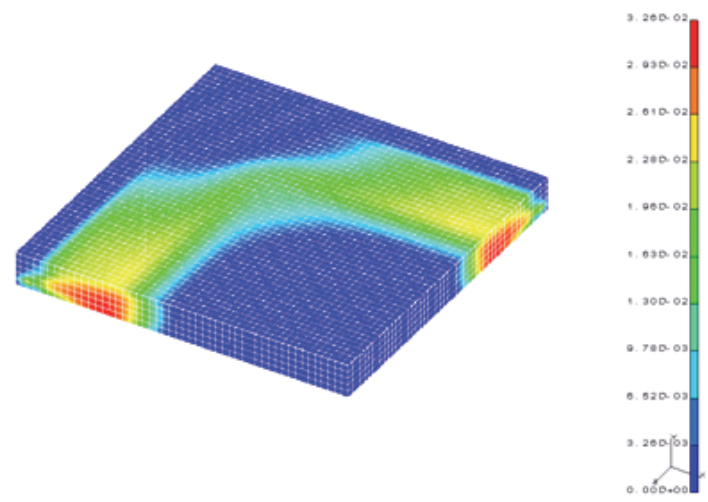

(a)

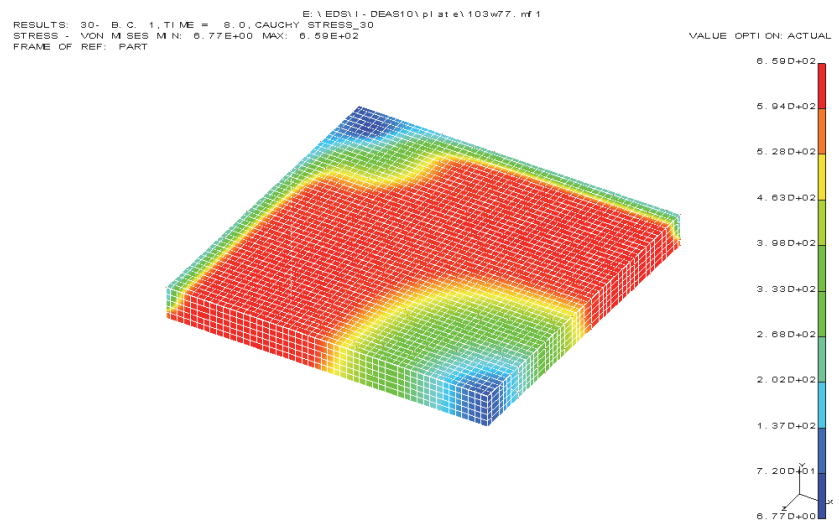


(b)

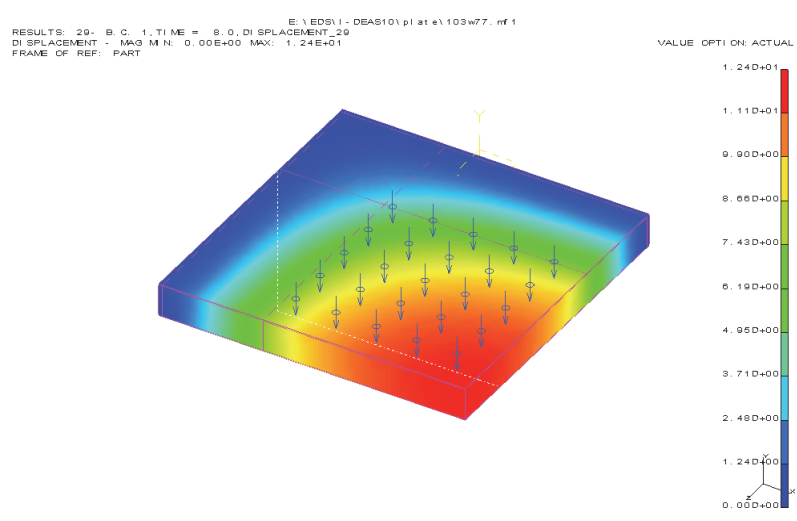

(c)

Figure 9. Illustration of A core material for loading area $(200 \mathrm{mmX} 200 \mathrm{~mm})$ and core thickness of $30 \mathrm{~mm}$ at load step $145 \mathrm{kPa}$, a) the core plastic deformations contour, b) Von Mises stress contour (in MPa) and c) the panel deformations contour

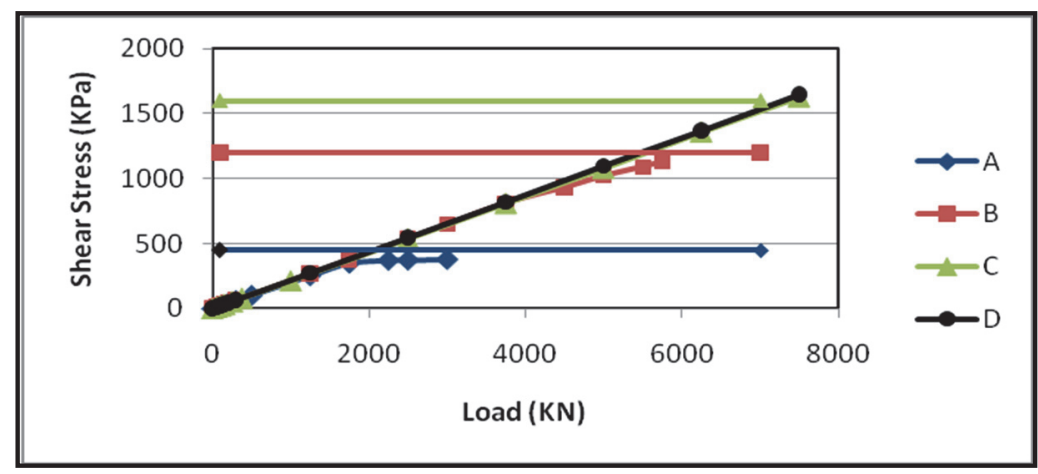

(a)

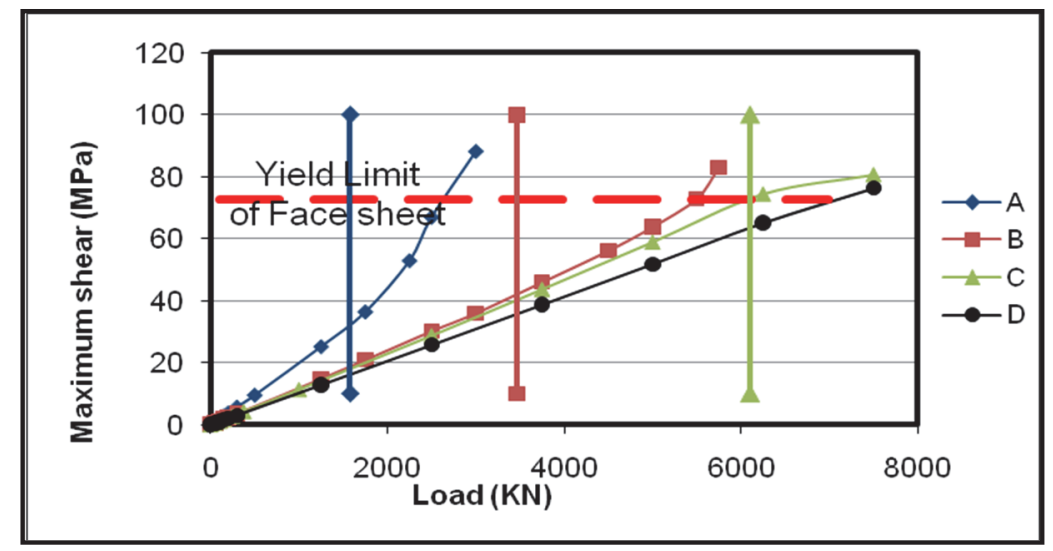

(b) 


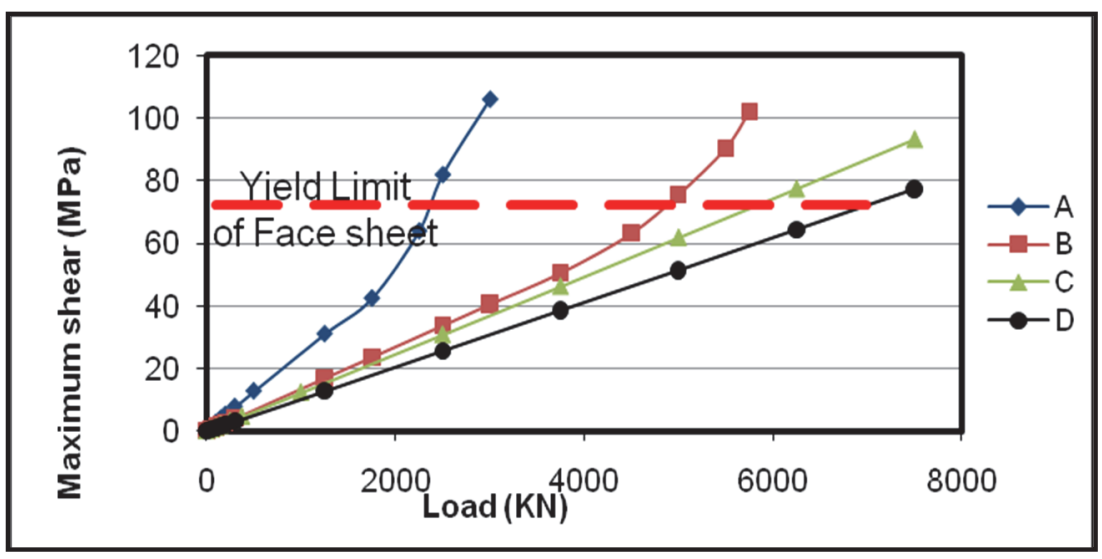

(c)

Figure 10. Illustration of maximum shear stress to shear yield stress versus load for a) core material, (b) lower Sheet and (c) upper Sheet

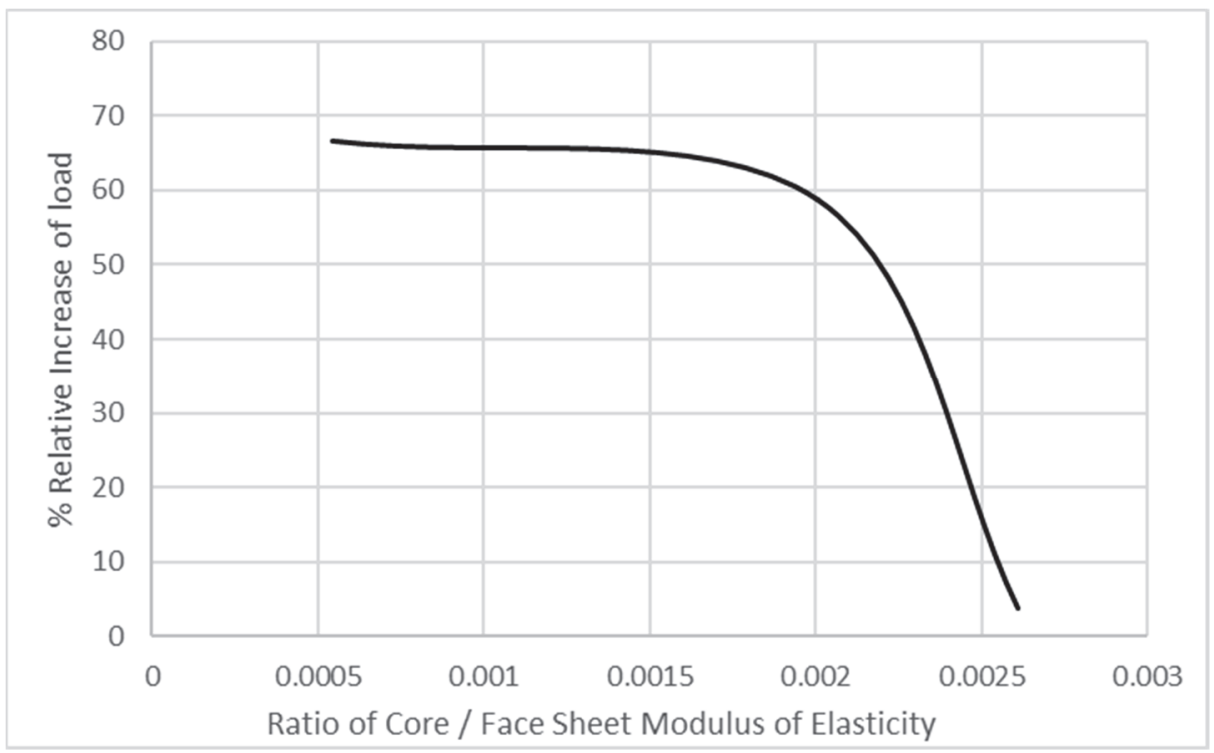

Figure 11. Illustration of the percent increase of load carrying capacity against the ratio of core to face sheet modulus of elasticity

\section{References}

Akour, S., \& Maaitah, H. (2010). Effect of Core Material Stiffness on Sandwich Panel Behavior Beyond the Yield Limit. Paper presented at the World Congress on Engineering, London, U.K.

Akour, S., \& Maaitah, H. (2012). Finite Element Analysis of Loading Area Effect on Sandwich Panel Behaviour Beyond the Yield Limit. In F. Ebrahimi (Ed.), Finite Element Analysis - New Trends and Developments (pp. 353-376). London-UNITED KINGDOM: Intech.

Akour, S., Maaitah, H., \& Nayfeh, J. (2012). Effect of Core Thickness on Load Carrying Capacity of Sandwich Panel Behavior Beyond Yield Limit. In A.-T. Evon, S. Asim El, \& J. Mostafa (Eds.), Technology Engineering and Management in Aviation: Advancements and Discoveries (pp. 171-181). Hershey, PA, USA: IGI Global.

Allen, H. G. (1969). Analysis and Design of Structural Sandwich Panels - 1st Edition: Pergamon Press, Oxford. ASTM-C273-94. (1994). Standard test method for shear properties of sandwich core materials (Vol. 15). 
ASTM-C297/C297M. (2004). Standard Test Method for Flatwise Tensile Strength of Sandwich Constructions (Vol. 03).

ASTM-C365/C365M-11a. (2011). Standard Test Method for Flatwise Compressive Properties of Sandwich Cores (Vol. 15).

ASTM-D6416/D6416-99. (1999). Standard Test Method for Two-Dimensional Flexural Properties of Simply Supported Composite Sandwich Plates Subjected to a Distributed Load (Vol. 15).

ASTM-E8/E8M-13a. (2013). Standard Test Methods for Tension Testing of Metallic Materials (Vol. 15).

Boyer, H. E., \& Gall, T. L. (1991). Metals Handbook. USA: American Society for Metals.

Caprino, G., \& Langella, A. (2000). Study of a three-point bending specimen for shear characterisation of sandwich cores. Journal of Composite Materials, 34(9), 791-814.

Chapra, S., \& Canale, R. (2006). Numerical Methods for Engineers (5th ed.). McGraw-Hill.

Frostig, Y., Baruch, M., Vilnay, O., \& Sheinman, I. (1992). High-Order Theory for Sandwich-Beam Behavior with Transversely Flexible Core. Journal of Engineering Mechanics-Asce, 118(5), 1026-1043. https://doi.org/10.1061/(asce)0733-9399(1992)118:5(1026)

Gdoutos, E. E., Daniel, I. M., Wang, K. A., \& Abot, J. L. (2001). Nonlinear behavior of composite sandwich beams in three-point bending. Experimental Mechanics, 41(2), 182-189. https://doi.org/10.1007/bf02323195

Kuang-An, W. (2001). Failure Analysis of Sandwich Beams. Northwestern University, Evanston, Illinois.

Mercado, L. L., \& Sikarskie, D. L. (1999). On the response of a sandwich panel with a bilinear core. Mechanics of Composite Materials and Structures, 6(1), 57-67. https://doi.org/10.1080/107594199305656

Mercado, L. L., Sikarskie, D. L., \& Miskioglu, I. (2000). Higher order theory for sandwich beams with yielded core. Paper presented at the 5th international conference on sandwich structures, Zurich.

Plantema, F. J. (1966). Sandwich construction : the bending and buckling of sandwich beams, plates, and shells. New York, USA: Wiley.

Rao, T. (2002). Study of Core Compression Using Digital Image Correlation (DIC). (Master of Science), Michigan Technological University, Houghton, Michigan.

Thomsen, O. T. (1993). Analysis of Local Bending Effects in Sandwich Plates with Orthotropic Face Layers Subjected to Localized Loads. Composite Structures, 25(1-4), 511-520. https://doi.org/10.1016/0263-8223(93)90199-z

Thomsen, O. T. (1995). Theoretical and Experimental Investigation of Local Bending Effects in Sandwich Plates. Composite Structures, 30(1), 85-101. https://doi.org/10.1016/0263-8223(94)00029-8

Triantafillou, T. C., \& Gibson, L. J. (1987). Minimum weight design of foam core sandwich panels for a given $\begin{array}{llll}\text { strength. Materials Science and Engineering, 95(Novmber), } & \text { 55-62. }\end{array}$ https://doi.org/10.1016/0025-5416(87)90497-6

Zenkert, D. (1995). An Introduction to Sandwich Construction: Engineering Materials Advisory Services.

\section{Appendix A}

\section{Analytical Model}

The following is derivation of the analytical model used in the analytical verification of the FEM. Classical Sandwich panel theory is used in developing this model.

Consider a sandwich plate with dimension $a . b$ as shown in Figure A.1. The positive senses for shear forces $\left(Q_{x}\right.$, $Q_{y}$ ) acting on the panel are shown in Figure A.2. The shear forces have units of force per unit length. 


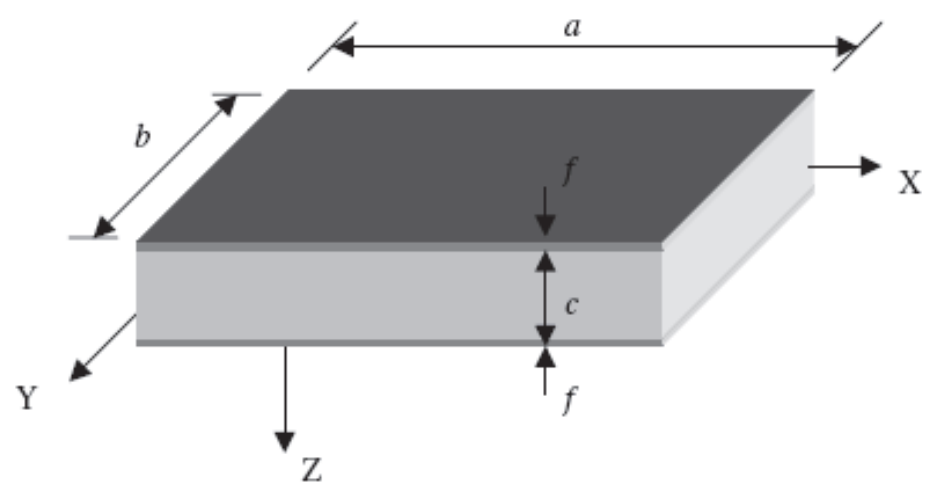

Figure A.1. Sandwich panel geometry

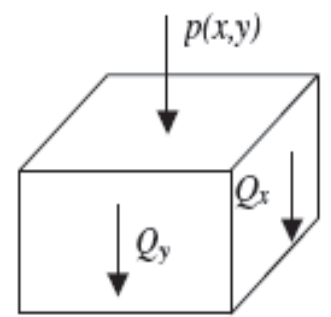

Figure A.2. Positive senses of forces

For sandwich plates that have a high overall length to thickness ratio, a small face sheet to overall thickness ratio, and a high face sheet to core mechanical properties ratio, the following assumptions are classically made:

1. Plane sections before deformation remain plane after deformation.

2. Transverse normal stiffness of core is infinite (i.e. no change in plate thickness).

3. Overall deflection is small compared to the thickness of the plate (i.e. no geometric non-linearity.

4. Slopes of the plate are small enough such that $\tan \left(\frac{d w}{d x}\right) \cong \frac{d w}{d x}$

5. The core carries the entire shear load and the face sheets carry all bending load.

6. The total displacement of the sandwich plate is the result of bending and shear deformation.

7. The strains are small enough that the linear strain displacement relationship is valid, i.e.

8. The core and face sheets are perfectly bonded.

$$
\mathcal{E}_{x}=\frac{\partial u}{\partial x}
$$

One of the assumptions in the classical sandwich plate theory is that the core carries the entire shear load. Therefore the shear load can also be expressed in terms of core shear rigidity and shear deflection:

$$
\begin{aligned}
& Q_{x}=\tau_{x z c} c=G_{c} c \gamma_{x z c}=S \frac{\partial w_{s}}{\partial x} \\
& Q_{y}=\tau_{y z c} c=G_{c} c \gamma_{y z c}=S \frac{\partial w_{s}}{\partial y}
\end{aligned}
$$

The boundary conditions for a simply supported sandwich panel are shown in Figure A.3. The total deflection and the second derivative of the bending deflection should vanish along the edges of the simply supported plate as shown in the figure. 


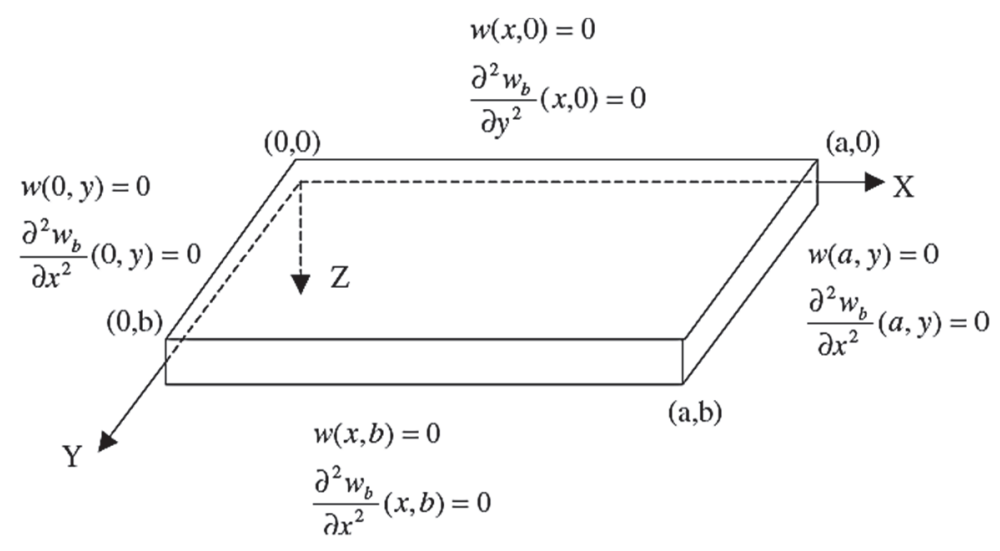

Figure A.3. Simply supported boundary condition for a sandwich panel

In order to find an expression that satisfies the simply supported boundary condition, a Fourier sine series solution, also called Navier's solution, is used. This solution automatically satisfies the expression of the bending deflection, shear deflection and the applied load terms within the simply supported panel under distributed load.

$$
\begin{array}{ll}
w_{s}(x, y)=\sum_{m}^{\infty} \sum_{n}^{\infty} r_{m n} \sin (\alpha x) \sin (\beta y) & m, n=1,2,3 \ldots . \\
p(x, y)=\sum_{m}^{\infty} \sum_{n}^{\infty} p_{m n} \sin (\alpha x) \sin (\beta y) & m, n=1,2,3 \ldots .
\end{array}
$$

Where $\alpha=\frac{m \pi}{a}$ and $\beta=\frac{n \pi}{b}, r_{m n}$, and $P_{m n}$ are unknown coefficients and $\mathrm{a}, \mathrm{b}$ are the length and the width of the panel between the support.

The step pressure model assumes a uniform distributed load applied on the surface of the sandwich panel over a corresponding square effective area. Figure C. 4 shows the schematic of the step pressure model.

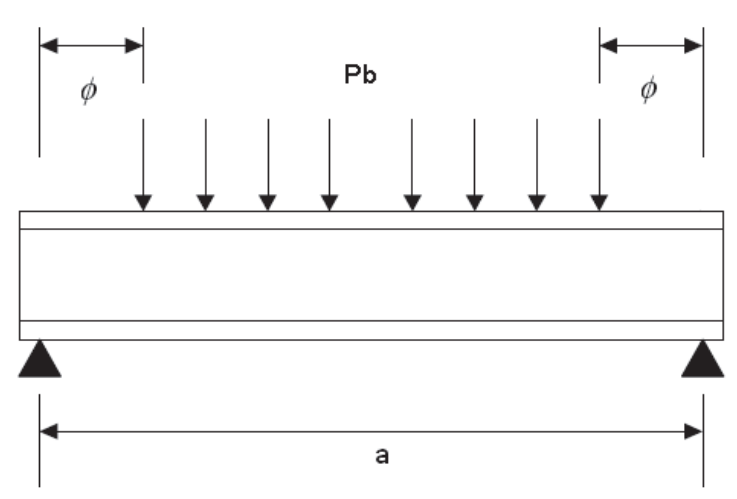

Figure A.4. Step pressure model on simply supported sandwich plate

This loading model can be represented mathematically as:

$$
P(x, y)=\left\{\begin{array}{lr}
P_{b} & \emptyset \leq x, y \leq(a-\emptyset) \\
0 & \text { elsewhere }
\end{array}\right.
$$


The effective contact area, $A_{\text {eff }}$ and the width of the unloaded region $\phi$ are given by the expressions:

$$
\phi=\frac{1}{2}\left(a-\sqrt{A_{\text {eff }}}\right)
$$

With the step pressure model defined, $r_{m n}$, and $p_{m n}$ can be determined by using equations A.3 and A.4

$$
\begin{aligned}
& p_{m n}=\frac{16 p_{b} \cos \left(\frac{m \phi \pi}{a}\right) \cos \left(\frac{m \phi \pi}{b}\right)}{\pi^{2} m n} \quad m, n=1,3,5 \ldots \\
& r_{m n}=\frac{p_{m n}}{S\left(\alpha^{2}+\beta^{2}\right)} \\
& m, n=1,3,5 \ldots .
\end{aligned}
$$

From equations A.1, A.2 and A.3, the shear stress components of the can be represented as:

$$
\begin{gathered}
\tau_{x z c}=G_{c 0} \frac{\partial w_{s}}{\partial x}=\sum_{m}^{\infty} \sum_{n}^{\infty} r_{m n} \cos (\alpha x) \sin (\beta y)\left(G_{c 0} \alpha\right) \\
\tau_{y z c}=G_{c 0} \frac{\partial w_{s}}{\partial y}=\sum_{m}^{\infty} \sum_{n}^{\infty} r_{m n} \sin (\alpha x) \cos (\beta y)\left(G_{c 0} \beta\right)
\end{gathered}
$$

In order to find the resultant shear load carried by the structure along any span pf the plate in the $X$ and $Y$-axes, equations A.9 and A.10 are integrated with respect to their respective cross section areas. The results are:

$$
\begin{aligned}
& Q_{x z c}=\int_{0}^{c} \int_{0}^{b} \tau_{x z c} d y d z=\sum_{m}^{\infty} \sum_{n}^{\infty} r_{m n} \cos (\alpha x)(1-\cos (\beta y))\left(\frac{c G_{c 0} \alpha}{\beta}\right) \\
& Q_{y z c}=\int_{0}^{c} \int_{0}^{b} \tau_{y z c} d y d z=\sum_{m}^{\infty} \sum_{n}^{\infty} r_{m n} \cos (\beta y)(1-\cos (\alpha a))\left(\frac{c G_{c 0} \beta}{\alpha}\right)
\end{aligned}
$$

\section{Copyrights}

Copyright for this article is retained by the author(s), with first publication rights granted to the journal.

This is an open-access article distributed under the terms and conditions of the Creative Commons Attribution license (http://creativecommons.org/licenses/by/4.0/). 